\title{
PLURALISMO JURÍDICO: UM NOVO PARADIGMA PARA SE PENSAR O FENÔMENO JURÍDICO
}

\author{
Joseane Catusso*
}

\section{RESUMO}

Considerando a importância da perspectiva sociológica para compreensão do fenômeno jurídico e a insuficiência do modelo clássico ocidental de legalidade positiva herdado do século XIX face à realidade plural e multifacetada da sociedade contemporânea, o artigo aborda o pluralismo jurídico como horizonte de uma nova legalidade, capaz de aproximar a produção do direito da sociedade civil. Dentre as polissêmicas propostas pluralistas, privilegia-se a análise do pluralismo comunitário participativo de Antônio Carlos Wolkmer, apresentado como um novo paradigma do direito baseado em práticas democráticas, compreensivo de um modelo alternativo de legalidade atuante por meio de uma prática coletiva atenta para a emergência dos sujeitos coletivos de jurisdicidade, que procura satisfazer as necessidades fundamentais do ser humano tomado como membro de uma sociedade solidária. Tal elaboração abrange, também, a imprescindibilidade de reordenação do espaço público por meio de uma política democrático-solidária, descentralizadora e participativa, na busca pela implementação de uma ética concreta de alteridade que contemple os momentos material e formal, tendo por base principal a realidade concreta.

Palavras-chave: pluralismo; relações sociais; comunitário; emancipação.

SUMÁRIO: 1 INTRODUÇÃO; 2 ModERNIDADE E MONISMO JURÍDICO; 3 AS PROPOSTAS PLURALISTAS: MULTIVOCIDADE; 4 O PLURALISMO COMUNITÁRIO PARTICIPATIVO DE WOLKMER; 4.1 OS NOVOS SUJEITOS COLETIVOS DE JURISDICIDADE; 4.2 SISTEMA DAS NECESSIDADES HUMANAS FUNDAMENTAIS; 4.3 REORDENAÇÃO DA POLÍTICA DO ESPAÇO PÚBLICO: DEMOCRACIA, DESCENTRALIZAÇÃO E PARTICIPAÇÃO; 4.4 ÉTICA CONCRETA DA

\footnotetext{
* Mestranda em Direito das Relações Social no Programa de Pós-graduação da UFPR. Email: josicatusso@hotmail.com
} 
ALTERIDADE; 4.5 RACIONALIDADE ENQUANTO NECESSIDADE E EMANCIPAÇÃO; 4.6 AINDA SOBRE A PROPOSTA PLURALISTA DE WOLKMER; 5 CONSIDERAÇÕES FINAIS; 6 REFERÊNCIAS.

\section{INTRODUÇÃO}

No âmbito das discussões sociológicas sobre as mudanças estruturais enfrentadas pela sociedade contemporânea, um dos elementos importantes é a preocupação acerca do grau de eficácia das regulamentações sociais e do modelo normativo vigentes. Esse ponto envolve discussões acerca da definição do espaço público e reconhecimento de novos sujeitos atuantes, bem como o redesenho das funções do Estado e das formas de participação democrática da sociedade civil. No contexto jurídico, o que ressalta é o debate em torno da emergência de uma regulação que não se resuma a disciplinar os anseios da classe dominante, mas que seja apta a oferecer respostas às carências e necessidades dos diversos atores sociais que compõem a plural e cambiante sociedade atual.

De fato, considerando-se que o direito sofre mudanças no decorrer do tempo e conforme variam as configurações espaciais, somado ao fato de que a sociedade contemporânea é essencialmente plural e multifacetada e que as necessidades e carências de todas as suas parcelas não podem ser resumidas em uma única proposta, parece factível afirmar que a realidade social concreta não pode ser refletida juridicamente como mera expressão da classe dominante ou das determinações do mercado. Dessa constatação surge a necessidade de se repensar a configuração do fenômeno jurídico na sociedade hodierna, aparecendo como fundamental a perspectiva sociológica ao percebê-lo como um fenômeno socialmente construído.

Especificamente no pano jurídico, observa-se que o modelo clássico ocidental de legalidade positiva começou a entrar em profunda crise a partir do final do século XX; crise esta que se espalha por seus fundamentos, objetivos e fontes de produção, gerando um quadro de distanciamento entre o direito formalmente vigente e o direito 
socialmente eficaz. A lenta corrosão dos pilares que sustentam a ordem jurídica de configuração moderna abre espaço para debate acerca das possibilidades de implementação de um projeto emancipador baseado nas condições históricas atuais e nas práticas reais. A análise sociológica do direito aparece justamente para considerar que o fenômeno jurídico situa-se numa realidade socialmente construída e possui caráter essencialmente histórico e social, já que se constitui a partir de relações sociais historicamente determinadas.

Por conseguinte, o que se busca é um novo paradigma para solução dos conflitos que emergem da vida comunitária, com uma regulação que supere o já inadequado modelo vigente, incapaz de solucionar eficazmente as demandas populares. É nesse espaço de insatisfação com a ordem vigente que surgem propostas para repensar sociologicamente novas normas de referência e legitimação para o jurídico, que ofereçam prioridade às necessidades mais imediatas da sociedade civil e envolvam um projeto cultural emancipador. As propostas de pluralismo jurídico aparecem nesse contexto, como horizontes de uma nova legalidade, capaz de captar as práticas reais da população, aproximando a produção do direito da sociedade civil.

Urge considerar, entrementes, que a expressão pluralismo jurídico é polissêmica, existindo quase tantos sentidos quantos são os seus representantes. Portanto, o objetivo deste trabalho restringe-se a analisar a proposta de pluralismo jurídico comunitário participativo de Antônio Carlos Wolkmer, sublinhando, concomitantemente, a relevância da análise sociológica do direito.

\section{MODERNIDADE E MONISMO JURÍDICO}

A partir de uma rápida análise do ordenamento jurídico contemporâneo já é possível perceber que o direito ainda ostenta as marcas modernas: apresenta-se a partir de uma dimensão autoritária, como fruto do poder do Estado, sob vestes formais que colocam a lei como fonte, por excelência, do direito. Contudo, apesar noções como 
legalidade, soberania, códigos, produção estatal do direito e monismo das fontes parecerem, em geral, características normais do direito, é interessante sublinhar que nem sempre foi assim. Essa identificação do direito com uma lei produzida pela autoridade estatal soberana é, historicamente, uma noção recente, fruto de uma escolha política, que vem sendo difundida nos últimos dois séculos apenas.

É interessante observar que em outros momentos históricos a experiência jurídica das sociedades já foi vivida de modo diferente, com a presença de práticas autônomas de elaboração legal comunitária. Wolkmer e Ehrlich destacam que, embora o direito do Império Romano tenha se apresentado com formalidades, instituições e aparato burocrático - mais tarde incorporados ao moderno direito estatal ocidental -, conviveu como formas autônomas de juridicidade, sem que isso diminuísse o poder político centralizado. Os romanos, ao lado de seu direito elaborado pelo poder central, permitiam que as populações conquistadas continuassem a aplicar o seu direito, como explica Wolkmer ${ }^{1}$. E Ehrlich acrescenta que os romanos utilizavam fontes não estatais, salientando a importância da distinção entre ius privatim e jus publicum, sendo o primeiro "o direito que repousa nas fontes não-estatais, o direito consuetudinário romano, em especial o direito romano dos juristas",

No mesmo sentido, cita-se o direito medieval ${ }^{3}$, que dominou o espaço europeu durante cerca de dez séculos, aparecendo como um direito fortemente ligado à sociedade civil, o que lhe oferecia complexidade e respeito à pluralidade de fontes. Sendo o poder político nesse período relativamente indiferente quanto à produção do direito, havia grande autonomia do jurídico que brotava espontaneamente dos fatos, no seio da comunidade, impondo-se mais em razão do conteúdo da norma do que de seu aspecto formal exterior.

É com o final da Idade Média e surgimento dos Estados modernos que emerge uma nova concepção de sociedade, fundada no capitalismo, demandando uma nova

${ }^{1}$ WOLKMER, Antônio Carlos. Pluralismo jurídico: fundamentos de uma nova cultura do direito. 2. ed. São Paulo: Alfa-Omega, 1997, p. 169.

${ }^{2}$ EHRLICH, Eugen. Fundamentos da sociologia do direito. Trad. René Ernani Gertz. Rev. Vamireh Chacon. Brasília: UnB, 1986, p. 333.

${ }^{3}$ Sobre a experiência jurídica medieval, ver GROSSI, Paolo. El ordem jurídico medieval. Trad. Francisco Tomas y Valente e Clara Álvares. Madrid: Marcial Pons, 1996, p. 45. 


\section{PLURALISMO JURÍDICO: UM NOVO PARADIGMA PARA SE PENSAR O FENÔMENO JURÍDICO}

configuração do fenômeno jurídico. O Code Napoleônico de 1804 surge como o máximo expoente dessa nova forma de expressão, marcando a história do direito por romper com as características da experiência jurídica medieval e inaugurar uma forma diferente de conceber o direito e o sistema das fontes, bem como por modificar profundamente a relação entre a ordem jurídica e o poder político. O que ressalta, nessa operação, é "o completo delinear de uma mentalidade energicamente nova que investe o coração da ordem jurídica, ou seja, o modo de conceber e de realizar a produção do direito" ${ }_{-}{ }_{-}$.

Essa transformação é apresentada concomitantemente à promessa de libertar os cidadãos das amarras da sociedade medieval, substituindo profundamente a questão das fontes do direito - passou-se do pluralismo medieval para o monismo moderno. Conclui Grossi, por conseguinte, que "o drama do planeta moderno consistira em realizar o processo de absorção de todo o direito na lei, na sua identificação na lei"6. Isso conduziu a um formalismo exacerbado, pois, reduzindo-se o direito a um conjunto de garantias formais, para que seja considerada 'lei' passa a se exigir certo procedimento pré-estabelecido. Não se pode afirmar que o conteúdo da lei passa a ser indiferente ao direito, mas é certo que seu conteúdo é indiferente para ditar sua observância, pois, tanto a lei justa como a lei injusta, formalmente editadas, possuem a

4 GROSSI, Paolo. Mitologias jurídicas da modernidade. Trad. Arno Dal Ri Junior. Florianópolis: Boiteux, 2004, p. 108. A descontinuidade entre a experiência jurídica medieval e moderna é também constatada por Pietro Costa, que reconhece esta como uma "discontinuità fondata sull'assolutistica 'piu colossale operazione di politica del diritto nell'intero arco della storia giuridica occidentale"”. CAPPELINI, Paolo. Il Códice eterno. La forma codici e suoi destinatari: morfolofie e matamorfosi di um paradigma della modernità. In: ; SORDI, Bernardo (a cura di). Codici: uma riflissione di fine millenio (atti dell'incontro di studio, Firenze, 26-28 ottobre 2000). Milano: Giuffrè, 2002. p. 35.

${ }^{5} \mathrm{O}$ movimento moderno oitocentista aparece com a pretensão de reduzir a complexidade social em um Código, apresentando-o como um sistema fechado e totalizante que tem na sua base as noções de igualdade formal e abstração. O direito é imposto de cima para baixo, marcado pela característica da autoridade e por um profundo monismo na sua produção, dado que apenas o ente estatal passa a estar legitimado a produzi-lo. E essa única fonte produtora, por certo, tutela seus interesses, apresentando um direito que responde à classe dominante da sociedade, protetivo da propriedade privada e da liberdade contratual. Interessante é observar que tais características são freqüentemente apresentadas como conquistas que devem ser preservadas. Nesse sentido, GROSSI: "de fato, é correntemente ensinado que são virtudes comuns da lei: os aspectos abstrato e geral, ou seja, a sua indiferença perante casos e motivos particulares; a rigidez, ou seja, a sua insensibilidade às possíveis diferentes exigências dos seus destinatários; a autoridade, ou seja, a indiscutibilidade do seu conteúdo”. GROSSI. Mitologias ..., p. 24.

\footnotetext{
${ }^{6}$ Ibidem, p. 50.
} 
mesma autoridade e devem ser por todos observadas.

Não é difícil imaginar, consequentemente, que essa lei, indiscutível e abstrata, inflexível, pensada desde um centro de poder distante do povo, acabe aparecendo aos olhos do homem comum como uma disposição exterior à sua realidade, afastada de seu cotidiano. Tal legalismo exacerbado aparece não como uma real garantia do cidadão, mas como uma indicação da preservação do sistema, mantendo-o como expressão da vontade do soberano e veículo para a perpetuação dos interesses da classe politicamente dominante.

As reduções operadas pelo modelo moderno, embora possam ter valores positivos - como a simplificação na apresentação da ordem jurídica e a harmonia interna decorrente da unicidade de fontes -, nem sempre foram bem sucedidas e podem ser alvo de muitas críticas. Um dos pontos negativos identificados é que a simplificação no sistema de fontes não resulta em maior liberdade individual, pois ao mesmo tempo em que permanecem os constrangimentos das ordens não legais, surge uma regulação jurídica em larga escala, muitas vezes distante da sociedade civil, abstrata e generalizada e, bem por isso, potencialmente mais opressora que as demais ordens de base consuetudinária. Atualmente, é possível observar a existência de uma nova complexificação do direito pela tentativa de reincorporar certos espaços normativos existentes nas comunidades locais antes excluídos, com uma proliferação de regulamentações especiais. E, nesse sentido, a proposta formal codificada mostra-se incapaz de responder aos anseios sociais, dado que a complexidade da sociedade é crescente e percebe no Código um instrumento inadequado tendente à generalidade, ao imobilismo e à perpetuidade, criticável em um contexto em que a velocidade das mudanças econômicas e sociais é grande.

Portanto, embora esse modelo possa ter respondido aos anseios da sociedade dos novecentos, sozinho não parece ser mais capaz de acompanhar as demandas da sociedade hodierna. É nesse contexto, de compreensão do projeto moderno e das demais experiências jurídicas históricas com ele não coincidentes, analisando-se suas características e limitações, que surgem elementos para delineamento de novas 
soluções jurídicas consentâneas aos reclamos atuais, dentre as quais, as propostas pluralistas.

\section{AS PROPOSTAS PLURALISTAS: MULTIVOCIDADE}

Os reflexos negativos do modelo moderno, com seus rigores formalistas decorrentes do centralismo jurídico estatal, favorecem, já no início do século XX, o surgimento de reações contrárias, com retomada do tema do pluralismo jurídico na preocupação de filósofos e sociólogos do direito. Dentre os publicistas e filósofos, estão Gierke, Haouriou, Santi Romano e Del Vecchio; entre os sociólogos, Ehrlich ${ }^{7}$ e Gurvitch. Além disso, durante as décadas de 50 e 60, houve a retomada do tema na antropologia jurídica pelos europeus, citando-se L. Pospisilo, Sally Falk Moore e John Griffiths ${ }^{8}$.

$\mathrm{Na}$ América Latina, pode-se identificar diversos autores que tratam do tema do pluralismo jurídico, entre os quais, Rangel, no México, German Palácio, na Colômbia e Carlos Cárcova, na Argentina. No Brasil, dentre os diversos teóricos, menciona-se Oliveira Vianna, André Franco Montoro, Joaquim de Arruda Falcão, José Geraldo de Souza Jr., Luiz Fernando Coelho, Eliane B. Junqueira, Edmundo de L. Arruda Jr., José

${ }^{7}$ Destes, destaca-se a obra de Ehrlich pela relevância que ofereceu à análise sociológica do Direito: segundo Ehrlich, a função primordial do Direito é o estabelecimento de uma ordem pacífica interna das relações sociais nas associações humanas, considerando que o centro gerador do Direito não está na legislação ou na jurisprudência, mas na própria sociedade, na forma como o direito aparece nas relações jurídicas travadas pelos membros da sociedade. Assim, designa por "direito vivo" o "direito existente independente do direito legislado, caracterizado como 'Direito vigente', é aquele que, apesar de não fixado em prescrições jurídicas, domina a vida" (MALISKA, Marcos A. Introdução à sociologia do direito de Eugen Ehrlich. Curitiba: Juruá, 2001 p. 71). Entendendo impossível aprisionar-se o direito de um povo ou de uma época em um Código, Ehrlich propõe que se comece a análise a partir do concreto, e não do genérico, pela observação dos documentos modernos e das práticas cotidianas. Com isso, não quer contrapor o direito vivo ao legislado, mas sublinhar que o direito não se restringe ao que foi positivado nas leis, dado que é, acima de tudo, um fenômeno social, e como tal deve ser estudado. A respeito, ver EHRLICH, op. cit.

${ }^{8}$ Segundo WOLKMER (PLURALISMO JURÍDICO. In: Dicionário de Filosofia do Direito. Vicente Barretto (org.). São Paulo: Unisinos; Rio de Janeiro: Renovar, 2006, p. 638). Também em WOLKMER. Pluralismo jurídico: fundamentos ..., p. 171-193. 
Eduardo Faria, Roberto Lyra Filho, Luís Alberto Warat e Albano Marcos Bastos Pêpe. E, por fim, registra-se a proposta de Antônio Carlos Wolkmer, a ser analisada mais detidamente.

Dessa multidão de representantes, importa destacar que as concepções apresentadas por cada um não são coincidentes: "pluralismo jurídico" é uma expressão essencialmente multívoca. Tratando-se de uma manifestação que emana de lugares diversos e em diferentes épocas, apresenta origens distintas e configurações múltiplas, sendo extremamente difícil apontar uma base comum, composta de princípios fundamentais, dado que as propostas vão desde configurações liberais ou radicais, até concepções de cunho conservador ou socialistas. A despeito da plurivocidade da expressão, Wolkmer assevera que:

esse cenário aberto, denso e díspar não nos impossibilita de admitir que o principal núcleo para o qual converge o pluralismo jurídico é a negação de que o Estado seja a fonte única e exclusiva de todo o Direito. Tal concepção minimiza ou nega o monopólio de criação das normas jurídicas por parte do Estado, priorizando a produção de outras formas de regulamentação, geradas por instâncias, corpos intermediários ou organizações sociais providas de certo grau de autonomia e identidade própria. Os pluralistas tendem a relativizar a onipotência do centralismo-formalista moderno de que o único Direito, com grau de obrigatoriedade e com reconhecimento oficial, é aquele emanado do poder do Estado, expresso sob a forma escrita e publicizada da lei ${ }^{9}$.

Logo, o pluralismo jurídico é um fenômeno relacionado à coexistência de práticas jurídicas distintas em um mesmo espaço ${ }^{10}$, ou seja, à coexistência de manifestações jurídicas estatais ou não, de "direito oficial" e "direito não-oficial". Distingue-se da "pluralidade do Direito", a qual se refere à existência de múltiplos direitos oficiais internos, e também do "uso alternativo do Direito", transcendendo-o, pois, ao passo em que este relaciona-se apenas à esfera de abrangência do direito

\footnotetext{
${ }^{9}$ WOLKMER. Pluralismo ..., p. 637-638.
}

${ }^{10}$ WOLKMER acrescenta que o pluralismo jurídico "envolve o conjunto de fenômenos autônomos e comparações heterogêneas que não se reduzem entre si. O pluralismo enquanto concepção filosófica toma em consideração que existem inúmeras fontes ou fatores causais para explicar não só os fenômenos naturais e cosmológicos, mas, igualmente, as condições de historicidade que cercam a própria vida humana. $\mathrm{O}$ pluralismo, enquanto multiplicidade dos possíveis, provém não só da extensão dos conteúdos ideológicos, dos horizontes sociais e econômicos, mas, sobretudo, das situações de vida e da diversidade de culturas". (Ibidem, p. 637). 
oficial, procurando explorar suas lacunas e ambigüidades em prol das classes menos favorecidas, o pluralismo jurídico pretende ter contato com outras manifestações jurídicas paralelas, ou concorrentes ao direito oficial.

Quanto às causas determinantes para o aparecimento desse fenômeno, Boaventura de Souza Santos identifica duas perspectivas: a origem colonial e a origem não colonial. A primeira refere-se à convivência, em um mesmo espaço, do direito trazido pelo Estado colonizador e do direito tradicional do local, o que acaba sendo fator "de conflitos e acomodações precárias"11. Tal situação ocorreu em espaços que foram dominados econômica e politicamente por outros países, levando-os a aceitar os padrões jurídicos trazidos pelo Estado dominante. Já a perspectiva não colonialista envolve, segundo Boaventura de Souza Santos, três contextos distintos: (a) países com tradições próprias que adotaram o direito europeu como "instrumento de modernização e consolidação do poder do Estado" 12 (ex. Turquia, Tailândia, Etiópia), ambiente no qual o pluralismo jurídico revela-se no fato de que o direito tradicional não foi eliminado das práticas cotidianas da população; (b) a segunda expressão do pluralismo não colonial ocorre quando, "em virtude de uma revolução social, o Direito tradicional entrou em conflito com a nova legalidade, o Direito revolucionário, tendo sido, por isso, proscrito, sem, no entanto, ter deixado de continuar a vigorar, em termos sociológicos, durante largo tempo"13 (ex. república da Ásia Central incorporadas pela antiga URSS); (c) por fim, menciona os casos de populações nativas que, não totalmente exterminadas, foram submetidas ao direito dos invasores, com a permissão de manterem seu direito tradicional em certos domínios (ex. populações indígenas da América Latina).

Tais situações apontadas por Boaventura de Souza Santos, por certo, não esgotam as possibilidades de práticas normativas; tratam-se, apenas, de casos consolidados de estruturas heterogêneas que servem para justificar sua proposta de um conceito ampliado de pluralismo jurídico, "de modo a cobrir situações susceptíveis de

${ }^{11}$ SANTOS, Boaventura de Souza. O discurso e o poder: ensaio sobre a sociologia da retórica jurídica. Porto Alegre: Fabris, 1988, p. 74.

${ }^{12}$ Ibidem, loc. cit.

${ }^{13}$ Ibidem, p. 75. 
ocorrer em sociedades, cuja homogeneidade é sempre precária porque definida em termos classistas, isto é, mas sociedades capitalistas"14.

Explica Maliska que o Brasil, historicamente, usando essa classificação apontada por Boaventura de Souza Santos, passou por três expressões de pluralismo jurídico: primeiramente, foi marcado pelo pluralismo colonial, com a implantação do direito oficial português, que mantinha uma relação de exclusão com o direito colonial tradicional, presente nas relações sociais, mas ignorado pelo direito oficial; a segunda expressão está relacionada aos povos indígenas que viviam à época da colonização, os quais mantinham práticas tradicionais à margem do direito oficial; por fim, "a expressão do pluralismo jurídico se dá em razão da exclusão social vivida pelo Brasil na condição de país capitalista atrasado" ${ }^{\prime 15}$. O precário desenvolvimento social do país produzindo grandes massas de excluídos propicia o surgimento de comunidades autônomas que buscam implementar regras de convivência próprias, paralelas àquelas disciplinadas pelo direito oficial. A rigor, é a ausência do Estado nesses grupos de excluídos que impossibilita a aplicação do direito oficial, criando uma lacuna geradora de pluralismo jurídico. É nessa terceira perspectiva que a questão do pluralismo jurídico vem sendo analisada atualmente, apresentando-se como um esforço na identificação de diversas formas de expressão do fenômeno jurídico que conduzam à apresentação de soluções para a parcela oprimida de cada sociedade, a partir de seus próprios valores. É nessa linha que se insere o pluralismo comunitário participativo de Antônio Carlos Wolkmer, buscando o resgate do pluralismo jurídico no contexto de um país marcado pela desigualdade e injustiça ${ }^{16}$.

Importante mencionar, também, que a tese do pluralismo jurídico tem merecido algumas críticas e objeções. Para Miguel Reale a dificuldade está em

${ }^{14}$ Ibidem, p. 76.

${ }^{15}$ MALISKA, Marcos Augusto. Pluralismo jurídico e direito moderno: notas para pensar a racionalidade jurídica na modernidade. Curitiba: Juruá, 2000, p. 31.

${ }^{16}$ Cumpre anotar que há, ainda, outras causas para o pluralismo jurídico, dentre elas: (a) a crise de legitimidade do regime oficial, que abre espaço para a possibilidade de baixa eficácia da legitimidade estatal e, consequentemente, o surgimento de manifestações normativas não-estatais; (b) "a 'ineficácia' e o caráter 'injusto' do paradigma hegemônico da legalidade dogmática estatal". Ambas são indicadas por Wolkmer com base nas teorizações de Joaquim A. Falcão e Jacques Vanderlinden, respectivamente. (WOLKMER. Pluralismo jurídico: fundamentos ..., p. 197. 
identificar e sistematizar "os grandes princípios do pluralismo legal""17, o que se deve à grande diversidade de proposições teóricas quanto ao tema, variando em seus elementos essenciais, além de agregar tendências das mais diversas que acabam contrastando entre si e excluindo-se. No mesmo sentido, Norberto Bobbio, que destaca o caráter ambíguo do pluralismo, que pode tanto servir a uma estratégia progressista, como a um projeto conservado. Também Jean Carbonnier chama atenção para o equívoco de algumas propostas exageradas, afirmando que "muitas situações qualificadas de pluralismo, como aquela entre o jurídico (Direito estatal) e o infrajurídico (Direito informal), na prática não perfazem ou constituem realmente pluralidade"18, ao passo que Cárcova aponta para o engano de se equiparar regras morais, religiosas ou costumes com as regras estatais obrigatórias ${ }^{19}$. Além disso, alguns teóricos da linha marxista criticam determinadas "generalizações que associam o 'direito não-oficial' ao direito espontâneo e popular", ${ }^{20}$, pois as diferenças, em certos casos, são mais aparentes que reais, e nem sempre o direito popular é mais autêntico ou justo que o estatal, além do que não está imune à manipulação do Estado.

Cumpre esclarecer, ademais, que se defende a idéia de que o pluralismo jurídico não deve negar o direito estatal, ou o direito oficial, mas tomá-lo como uma das diversas manifestações que o fenômeno jurídico pode assumir na sociedade. Destarte, o pluralismo envolve tanto as práticas oficiais quanto aquelas independentes ou semi-autônomas em relação ao Estado. E, partindo desse reconhecimento para além do direito estatal, a perspectiva pluralista possui o mérito de oferecer autenticidade às múltiplas manifestações normativas não-estatais originadas na sociedade, o que, inserindo-se em um espaço de conflitos e de relações marcadas pela desigualdade e exclusão de certos setores sociais, contém a possibilidade de inclusão de parcelas atualmente alijadas e reconhecimento de seus direitos.

Ao considerar os limites do pluralismo jurídico, Wolkmer destaca as teorizações

\footnotetext{
${ }^{17}$ REALE, Miguel apud WOLKMER. Pluralismo jurídico: fundamentos ..., p. 203.

${ }^{18}$ WOLKMER. Pluralismo ..., p. 639.

${ }^{19}$ Ibidem, loc. cit.

${ }^{20}$ WOLKMER. Pluralismo jurídico: fundamentos ..., p. 204.
} 
de Norbert Rouland ${ }^{21}$, para quem o pluralismo poderia ser atenuado, reduzido e progressivamente desaparecer com a 'depluralização', que poderia ocorrer em duas situações: (a) quando há uma grande homogeneização da sociedade, na qual desaparecem as várias formas de direito paralelo; (b) quando um órgão central impõe a unidade do sistema, incorporando o direito paralelo ao direito oficial ${ }^{22}$. A despeito dessas considerações, parece evidente que toda estrutura societária é composta por heterogeneidades, por elementos diversos, e muito dificilmente ter-se-á, na realidade concreta, uma sociedade absolutamente homogênea.

Ademais, Wolkmer ressalta que se o modelo do pluralismo tradicional, utilizado e defendido pelas classes sociais hegemônicas, está ultrapassado, isso não significa a inutilização de um outro tipo de pluralismo de caráter aberto, "identificado plena e autenticamente com as condições objetivas de mudança e emancipação de sociedades de cultura periférica liberal-burguesa como a nossa" ${ }^{\text {23 }}$. É na perspectiva deste pluralismo aberto e ampliado que Wolkmer apresenta uma proposta que coordena a perspectiva do nível jurídico - pluralismo legal - e dos níveis social e político - pluralismo comunitário-participativo.

\section{O PLURALISMO COMUNITÁRIO PARTICIPATIVO DE WOLKMER}

Na obra "Pluralismo Jurídico: fundamentos de uma nova cultura no Direito", Wolkmer apresenta uma nova perspectiva para o Direito, consubstanciada em um paradigma original que tem por fundamento um viés pluralista e democrático, tomando por base o seguinte conceito de pluralismo jurídico: "a multiplicidade de práticas

${ }^{21}$ ROULAND, Norbert apud WOLKMER. Pluralismo jurídico: fundamentos ..., p. 205.

${ }^{22}$ Exemplo do primeiro caso é o nivelamento pelo sufrágio universal, e do segundo, quando as reivindicações por direitos são incorporadas pelo direito oficial.

${ }^{23}$ WOLKMER. Pluralismo jurídico: fundamentos ..., p. 206. A principal diferença entre ambos os pluralismos está em que enquanto o tradicional prega um pluralismo elitista, o aberto propõe uma abertura à participação popular e dos novos sujeitos coletivos. 
jurídicas existentes num mesmo espaço sócio-político, interagidas por conflitos ou consensos, podendo ser ou não oficiais e tendo sua razão de ser nas necessidades existenciais, materiais e culturais",24.

Ao analisar tal proposta é importante atentar para o fato de que referido autor pretende apresentar uma alternativa para o atual modelo de legalidade por meio de uma prática pluralista que atente para a emergência de um novo sujeito, identificado na figura do sujeito coletivo, satisfazendo as necessidades fundamentais do ser humano tomado como membro de uma sociedade solidária, e abrangendo a reordenação do espaço público por meio de uma política democrático-comunitária, descentralizadora e participativa, com o que busca implementar uma ética concreta de alteridade que contemple os momentos material e formal, tendo por base principal a realidade concreta. Na visão de Wolkmer, "o pluralismo deve corresponder a um novo paradigma do Direito compreendido como projeto comunitário participativo" 25 .

Assim, centrando seu estudo na realidade latino-americana, parte da constatação do esgotamento dos paradigmas marcados pelo liberalismo individual, pelo racionalismo instrumental e pelo formalismo positivista, até então vigentes, a serem superados tanto por “contradiscursos desmistificadores que têm um amplo alcance teórico-crítico, quanto por novas proposições epistemológicas fundadas na experiência histórica e na prática cotidiana concreta de um pluralismo jurídico de teor comunitário-participativo" ${ }^{26}$. Propõe, então, um novo tipo de pluralismo jurídico ampliado, que abrange a rediscussão de questões como fontes, fundamentos e objeto do direito, compreendendo elementos de eficácia material e formal ${ }^{27}$. Seguindo a linha de um pluralismo progressista, de base democrático-participativa, Wolkmer explica que sua proposta refere-se a:

${ }^{24}$ Ibidem, p. 195.

${ }^{25}$ MALISKA. Pluralismo ..., p. 61.

${ }^{26}$ WOLKMER. Pluralismo jurídico: fundamentos ..., p. 208.

${ }^{27}$ Os fundamentos materiais, ligados ao conteúdo, referem-se aos sujeitos coletivos e à satisfação das necessidades humanas essenciais; o momento formal, por sua vez, liga-se às questões de ordenação prático-procedimental, referindo-se ao processo democrático de descentralização, participação e controle comunitários, englobando a construção de uma ética concreta de alteridade e de processos referentes a uma racionalidade emancipatória. 
um novo pluralismo jurídico (designado de comunitário-participativo) configurado num modelo aberto e democrático, privilegiando a participação direta dos sujeitos sociais na regulação das instituições-chave da Sociedade e possibilitando que o processo histórico se encaminhe pela vontade e controle das bases comunitárias. Reitera-se nessa tendência, antes de mais nada, a propensão segura de se visualizar o Direito como um fenômeno resultante de relações sociais e valorações desejadas, de se instaurar uma outra legalidade a partir da multiplicidade de fontes normativas não obrigatoriamente estatais, de uma legitimidade embasada nas 'justas' exigências fundamentais de atores sociais e, finalmente, de encarar a instituição da Sociedade como uma estrutura descentralizada, pluralista e participativa ${ }^{28}$.

Essa proposta pressupõe a articulação dos seguintes elementos, de ordem material e formal:

\subsection{OS NOVOS SUJEITOS COLETIVOS DE JURISDICIDADE}

Iniciando com um dos fundamentos de efetividade material, Wolkmer referese aos novos sujeitos coletivos de jurisdicidade como uma nova definição de sujeito jurídico, que vem reconhecido como "sujeito histórico em-relação", "povo" e "outro". Entende que os novos sujeitos coletivos compreendem "aqueles estratos sociais participativos e geradores de produção jurídica, dando forma e priorizando o que se convencionou chamar de 'novos movimentos sociais' (ainda que não se reduza única e tão somente aos mesmos)" ${ }^{29}$. Observa-se, desde logo, que o autor priorizou os movimentos sociais como parcelas participativas e geradoras de elementos jurídicos na sua análise do pluralismo jurídico.

Essa idéia do novo sujeito coletivo concreto contrasta com a noção abstrata de sujeito individual da modernidade. Assim, enquanto esse sujeito moderno abstrato e individual é "o sujeito cognoscente a priori, que se adequa às condições do objeto dado e à realidade global estabelecida, o 'novo sujeito coletivo' é um sujeito vivo, atuante e livre,

\footnotetext{
${ }^{28}$ WOLKMER. Pluralismo jurídico: fundamentos ..., p. 69.

${ }^{29}$ Ibidem, p. 210.
} 
que se autodetermina, participa e modifica a mundialidade do processo histórico-social"30. Assim, os sujeitos coletivos não devem ser tomados como uma totalidade constituída por sujeitos soberanos, mas como um espaço composto por identidades heterogêneas em constante processo de construção e definição ${ }^{31}$.

Maliska, a partir da obra de Wolkmer, sistematiza a distinção entre "antigos" e "novos" movimentos sociais: até o final da década de 60, nas sociedades capitalistas, predominou os movimentos sociais constituídos, em grande parte, pela classe operária, fortemente influenciada pelos princípios do socialismo, marxismo e anarcosindicalismo; já os novos movimentos, predominantes nas décadas de 70 e 80, surgem a partir de fatores como a insegurança da população face à impotência das clássicas instituições políticas e a falência do Estado Social, entre outros, identificando-se neles a possibilidade de emergência de um novo paradigma cultural e de uma organização social emancipatória ${ }^{32}{ }^{33}$.

Interessante sublinhar, ainda, que a articulação desses movimentos não ocorreu apenas para reivindicar direitos ao Estado: acabaram criando certa independência e autonomia que lhes permitiu a implementação de uma forma paralela de solução de seus problemas, com a participação de $\operatorname{todos}^{34}$. Tais movimentos

${ }^{30}$ Ibidem, p. 211.

${ }^{31}$ Logo, não se pode pensar os novos sujeitos coletivos em termos de identidades humanas como sexo, raça, idade ou religião, mas a partir da tomada de posição que permitiu que minorias oprimidas passassem a ser sujeitos participantes na criação de sua história.

${ }^{32}$ MALISKA. Pluralismo ..., p. 67.

33 "Dentre os fatores conjunturais que elucidam o fenômeno dos movimentos sociais no Brasil, a reivindicação de interesses compartilhados dentro de um esforço comum talvez tenha sido o maior propulsor da emergência dos novos movimentos sociais. O crescimento desordenado das grandes cidades tornou imperativa a organização das classes populares para que fosse possível obter do Estado a prestação de serviços públicos básicos (...). O fundamental é a força do engajamento coletivo que cobra do Estado a prestação dos serviços públicos à comunidade, pois uma reivindicação individual não surte efeito". (Ibidem, p. 68-69).

${ }^{34}$ Maliska, com base em Wolkmer, indica alguns elementos caracterizadores dos novos movimentos sociais: quanto ao conteúdo, relacionam-se à satisfação das necessidades básicas; quanto aos valores e princípios, impulsionam uma nova cultura jurídica participativa, assentada na democracia de base, direito à diversidade, à individualidade, à identidade local, compreendendo os valores da identidade e autonomia; quanto às formas de ação, rompem com o modelo tradicional de representação e organização política, apresentando uma estrutura que exige constante participação do corpo social, tanto na tomada de decisões, quanto no processo de execução. 
mesclam uma postura reinvindicatória (pressionando o Estado para obtenção de melhores condições de vida), contestatória (a partir das carências da população, de oposição ao poder estatal, introduzindo propostas alternativas para cuidar de demandas não alcançadas pelo Estado) e participativa (pregando a descentraliazação do poder e ampliação da participação popular). Identificando que nem todos os movimentos sociais coincidem com as classes populares, havendo alguns que se beneficiam com a manutenção do sistema, Wolkmer apresenta o seguinte conceito de "novos sujeitos coletivos":

são situados como identidades coletivas conscientes, mais ou menos autônomos, advindos de diversos estratos sociais, com capacidade de auto-organização e auto-determinação, interligadas por formas de vida com interesses e valores comuns, compartilhando conflitos e lutas cotidianas que expressam privações e necessidades por direitos, legitimando-se como força transformadora do poder e instituidora de uma sociedade democrática, descentralizadora, participativa e igualitária ${ }^{35}$.

Destarte, considera que, se os movimentos sociais são vistos como sujeitos que podem lutar pela implementação de direitos já formalmente assegurados, bem como atuar como uma nova fonte de legitimação jurídica, é correto equipará-los à categoria de novos sujeitos coletivos, possiblitando seu enquadramento na esfera de incidência jurídica. Observe-se, ainda, que a importância da demonstração da categoria dos novos sujeitos coletivos não está na sua transformação em objeto de si mesmo, mas na relação de alteridade, buscando a satisfação de necessidades e clamando por direitos.

\subsection{SISTEMA DAS NECESSIDADES HUMANAS FUNDAMENTAIS}

As condições precárias de vida de grande parte da população estimulam a criação de vias para reinvindicação dos seus direitos, entendendo Wolkmer que é "com o aparecimento dos novos sujeitos coletivos de juridicidade, internalizados nos 
movimentos sociais, que se justifica e se legitima todo um complexo 'sistema de necessidades" ${ }^{, 36}$. Por necessidades Wolkmer não entende apenas aquelas de ordem social ou material, mas inclui as necessidades existenciais, de subsistência e culturais, considerando, ainda, que as necessidades são espacial e temporalmente inesgotáveis, não podendo ser satisfeitas completamente, até porque há o constante aparecimento de novas necessidades face às cambientes condições sociais de vida.

A partir das teorizações de Marx, Weber, e, principalmente, de Agnes Heller que, segundo Wolkmer é quem melhor trabalha a teoria das necessidades, a partir dos marcos teóricos marxista-lukácsianos ${ }^{37}$-, Wolkmer conclui que

ao avaliar-se o desenvolvimento conjuntural e estrutural do Capitalismo nas sociedades latino-americanas, parece clara a forte tendência de se priorizar uma interpretação 'determinista'ou 'sócio-econômica'de toda uma globalidade de necessidades básicas insatisfeitas. Isso justifica-se, historicamente, porquanto as condições valorativas, estruturais e institucionais favorecem leituras das 'necessidades' como resultantes de carências primárias e diretas, de lutas e conflitos gerados pela divisão social do trabalho e por exigências de bens e serviços vinculados à vida produtiva. Mesmo que a hipótese do 'determinismo estrutural' possa ser incisiva e preponderante quando se opera com as esferas públicas e periféricas (caso do Brasil), desintegradas pelos níveis de qualidade, bem-estar e materialidade social de vida, não se pode e não se deve omitir as variáveis culturais, políticas, éticas, religiosas e psicobiológicas ${ }^{38}$.

${ }^{35}$ WOLKMER, Antônio Carlos. Pluralismo jurídico: fundamentos ..., p. 214.

${ }^{36}$ Ibidem, p. 216.

${ }^{37}$ Agnes Heller propõe, em sua Teoria das necessidades em Marx, uma reflexão sobre os diferentes tipos de necessidades humanas, as razões que as criam e suas caracterizações quantitativas e qualitativas. Heller entende que "as condições econômicas geradas pelo Capitalismo impedem a satisfação das necessidades essenciais, determinando um sistema de falsas necessidades, sedimentadas basicamente na divisão do trabalho, nas leis do mercado e na valorização do capital" (HELLER apud WOLKMER, ibidem, p. 219). Em trabalho posterior (Políticas da pós-modernidade), a referida autora constata que a lógica da modernidade ocidental vem impulsionada por uma força motivadora que institui uma "sociedade insatisfeita", marcada por contínuas mudanças e povoada por sujeitos individuais e coletivos. E WOLKMER constata que o sentimento de satisfação, nessa sociedade insatisfeita, surge da possibilidade que cada membro possui de "atuar sobre o processo de contingência e comprometer-se com a realização das necessidades de autodeterminação dos demais" (ibidem, p. 221). Ainda conforme salienta MALISKA, mesmo que Agnes Heller considere a democracia formal como condição preliminar para a satisfação das necessidades radicais e para o surgimento dos movimentos que as reinvindicam, entende que ela não é uma premissa suficiente para o efetivo atendimento das carências (MALISKA. Pluralismo ..., p. 81), dado que a efetivação e a força que impulsiona os movimentos sociais depende do sistema de necessidades insatisfeitas, apresentando reivindicações de ordem social, política e culturalespiritual, o que os torna "potencialidade emancipadora" e fonte de legitimação de um direito próprio.

${ }^{38}$ WOLKMER. Pluralismo jurídico: fundamentos, p. 221. 
Logo, Wolkmer considera que o conjunto de necessidades humanas fundamentais tem sua causa em um amplo leque de fontes de ordem quantitativa e qualitativa, objetivas e subjetivas, materiais e imateriais, reais e ilusórias etc., e que é nas condições sociais brasileiras, marcadas por conflitos, contradições e insatisfação dessas necessidades, que estão os movimentos sociais, lutando pela implentação de direitos já adquiridos ou reconhecimento de novos.

\subsection{REORDENAÇÃO POLÍTICA DO ESPAÇO PÚBLICO: DEMOCRACIA, DESCENTRALIZAÇÃO E PARTICIPAÇÃO}

Juntamente aos fundamentos de efetividade material, é necessário, segundo Wolkmer, a implementaçao de estratégias de efetividade formal, o que abrange as condições para a realização de uma política democrática tendente a produzir um espaço comunitário descentralizado e participativo. Reconhecendo que tal transformação não será feita a curto prazo ou de forma simples em sociedades como a brasileira, marcada por uma "tradição político-cultural centralizadora, dependente e autoritária" 39 , Wolkmer destaca que está a falar de uma profunda ruptura com relação à atual estutura societária: tendo em vista que a organização do território formou-se a partir da imposição do capital internacional, de interesses das elites detentoras da hegemonia política, econômica e cutural, que promove modificações independentes da participação dos setores regionais, passa a falar de complexas alterações no modo de vida cotidiano, com reordenação do espaço público individual e coletivo, "resgatando ações humanas que passam pelas questões da 'comunidade', 'políticas democráticas de base', 'participação e controle popular', 'gestão centralizada', 'poder local ou municipal' e 'sistema de conselhos", ${ }^{\prime 40}$.

Não se trata aqui da comunidade do século XVIII, como ordem social fundada

\footnotetext{
${ }^{39}$ Ibidem, p. 222-223.

${ }^{40}$ Ibidem, p. 223.
} 


\section{PLURALISMO JURÍDICO: UM NOVO PARADIGMA PARA SE PENSAR O FENÔMENO JURÍDICO}

na universalidade formal e composta de sujeitos abstratamente homogêneos, mas de uma comunidade permeada por sujeitos dinâmicos e participativos. Importante, entretanto, sublinhar a insuficiência de políticas de pariticipação comunitária implementadas e controladas pelo Estado, pois podem ser clientelísticas, sendo obrigatório, na visão de Wolkmer, pensar-se em um espaço público composto por novas forças sociais - os movimentos sociais - que atuem com vistas a real satisfação das necessidades fundamentais e como instâncias produtoras de um direito comunitário autônomo. Além de que, todas as propostas de transformação de organização do espaço público devem possuir, atualmente, bases em políticas democráticas fundadas na descentralização, participação e controle das bases ${ }^{41}$.

Anote-se, também, que a participação deve provir de um constante processo de interação entre os sujeitos coletivos de juridicidade e o poder legitimamente instuído, sendo que Wolkmer indica condições e instrumentos para essa participação popular. Quanto às condições, com base nas lições de Pedro Jacobi, destaca dois requisitos essenciais: “a) a presença de organizações de interesse popular na esfera pública local; b) a ocupação estratégica de cargos ou funções também no âmbito distrital ou municipal por parte de indivíduos, lideranças ou partidos comprometidos com as causas comunitárias" ${ }^{42}$. No que concerne aos mecanismos de participação, Wolkmer destaca a importância de instrumentos de participação no âmbito dos três Poderes $^{43}$.

${ }^{41}$ Nesse sentido, entende WOLKMER que, em estruturas autoritárias, centralizadoras e excludentes, como a brasileira, para reordenação do espaço comunitário mister a "construção de uma verdadeira cidadania aliada ao desenvolvimento de uma democracia participativa de base que tenha como meta a descentralização administrativa, o controle comunitário do poder e dos recursos, o exercício de mecanismos de co-gestão local/setorial/municipal e o incremento das práticas de conselhos ou juntas consultivas, deliberativas e executivas" (ibidem, p. 226). É certo, ainda, que a construção de uma sociedade democrática com base nas identidades locais depende não apenas de uma integral participação de cidadania consciente e atuante, mas também de descentralização político-administrativa e redistribuição racional de recursos, competências e funções. E WOLKMER conclui que "a implementação e o alargamento da sociedade democrática descentralizadora só se completa com a efetiva participação e controle por parte dos movimentos e grupos comunitários" (ibidem, p. 227), os quais são capazes de exercer o controle democrático sobre o Estado ou qualquer forma de poder instituído.

42 JACOBI, Pedro apud WOLKMER, ibidem, p. 228.

${ }^{43}$ Quanto aos mecanismos de participação nas esferas dos três poderes do Estado, Wolkmer vale-se das lições de Abreu Dallari. Assim, quanto ao Legislativo, são seis as medidas indicadas: a) poder de 
Por fim, destaca-se que essas propostas alcançam plena significação se houverem, no espaço comuntário, formas de democracia participativa de base, pois, conforme ensina Bobbio $^{44}$, a ampliação da democracia decorre tanto da participação e da liberdade de dissenso, quanto de um processo de expansão do poder ascendente em diversas articulações. Nesse sentido, Wolkmer considera que a forma democrática mais autêntica de participação, deliberação e controle, é o sistema de conselhos, espalhado nos diversos níveis de poder local, capaz de efetivar no âmbito político uma democracia pluralista.

\section{4 ÉTICA CONCRETA DA ALTERIDADE}

Ainda no nível da efetividade formal, Wolkmer entende necessária a configuração de uma nova ordem de valores éticos. Partindo da constatação do esgotamento da cultura projetada pela modernidade, Wolkmer percebe que existe uma crise de legitimação normativa que perpassa as instituições políticas, econômicas, e também as idéias e práticas valorativas, e observa que uma das grandes dificuldades atuais "é arquitetar as bases de um conjunto de valores éticos capazes de internalizar o 'eu' individual e o 'nós' enquanto comunidade real",45. Trata-se da busca de novas balizas para efetivação de um projeto cultural marcado pela democracia, por uma ordem humanitária e de valorização do ser humano que vive em uma comunidade solidária e não excludente.

Quanto à questão da ética, Wolkmer parte da exposição sucinta de duas

iniciativa da comunidade com vinculação para os governantes; e c) prática do plebiscito e do referendum; d) 'veto popular'; e) audiências públicas para deliberação sobre futuros projetos; f) ato de revogação do mandato e reconfirmação para representante político ou comunitário. $\mathrm{Na}$ esfera da Administração, indica: a) a participação do povo no planejamento; b) consulta à comunidade sobre o orçamento; c) representação da comunidade em órgãos consultivos e da administração descentralizada; d) participação popular no exercício de um poder de controle. Por fim, no Judiciário, as medidas envolvem a democratização do acesso à Justiça; criação de tribunais distritais de habitação e consumidores; centros de justiça de bairros; comitês de conciliação e mediação etc. Segundo DALLARI apud WOLKMER, ibidem, p. 228-230.

\footnotetext{
${ }^{44}$ Bobbio, Norberto apud WOLKMER, ibidem, p. 230.

${ }^{45}$ Ibidem, p. 234.
} 
contribuições filosóficas que procuram oferecer respostas para o exaurimento dos valores éticos da modernidade. A primeira é o pragmatismo analítico, que rejeita os princípios ético universais por entender que é desnecessário, e mesmo prejudicial, buscar normas gerais, dado que a ética cinge-se a regras imediatas e particulares. Considerando essa proposta conservadora e insuficiente, Wolkmer menciona o racionalismo discursivo, destacando as contribuições de Jürgen Habermas e Karl-Otto Apel para a teoria da racionalidade comunicativa, os quais "procuram edificar as condições para uma ética universalista do discurso prático-comunicativo que objetive uma maior assimilação entre o 'eu' individual e a autonomia das identidades coletivas" 46 . A ética do discurso traz a proposta de uma 'macroética pós-convencional', com validade para toda a humanidade, requerendo uma "validade universal intersubjetiva independente das circunstâncias"47.

Ainda que Wolkmer elogie as contruibuições da ética discursiva no tocante à relevância de suas análises e às suas categorias-chave ${ }^{48}$, entende que é necessário um desenvolvimento ulterior, pois tal proposta parte da premissa da existência de uma condição a priori, que é a comunidade de comunicação ideal, da qual todos participam e são iguais no jogo argumentativo, o que, efetivamente, não ocorre nas sociedades do capitalismo periférico, compostas por sujeitos desiguais. E, sendo assim, aqueles que deveriam participar da comunidade de comunicação representando a voz do 'outro' são ignorados e excluídos.

Considerando essa realidade, Wolkmer propõe um avanço na direção da formulação de uma "ética da alteridade", "capaz de romper com todos os formalismos técnicos e os abstracionismos metafísicos, revelando-se a expressão autêntica dos valores culturais e das condições histórico-materiais do povo sofrido e injustiçado da

\footnotetext{
${ }^{46}$ Ibidem, p. 236.

${ }^{47}$ Embora criticado pelo pós-estruturalismo, APEL afirma que, hodiernamente, há necessidade de se buscar valores universais e que isso não prejudica a diferença e a particularidade, ao que WOLKMER acrescenta que a intenção apeliana não está em "oferecer uma ética acabada para uma realidade constituída de diferentes grupos particulares, mas sim princípios universais condutores que deverão ser usados como direção geral, princípios que ordenam uma ética coletiva da responsabilidade, envolvendo a participação de todos para o bem-estar e a felicidade geral". (Ibidem, p. 238).

${ }^{48}$ Como as categorias de responsabilidade, práxis emancipatória, solidariedade, valorização das subjetividades do mundo da vida e consenso da comunidade real.
} 
periferia latino-americana e brasileira" ${ }^{49}$. É uma ética libertária, porque está inserida e é produto das práticas sociais, envolvendo duas condições essenciais: “a) inspira-se na 'praxis concreta' e na situação histórica das estruturas sócio-econômicas até hoje espoliadas, dependentes, marginalizadas e colonizadas; b) as categorias teóricas e os processos de conhecimento são encontrados na própria cultura teológica, filosófica e sócio-política latino-americana" ${ }^{, 50}$.

Portanto, trata-se de uma ética que, ao mesmo tempo em que contempla princípios universalizantes, prioriza as práticas culturais de uma historicidade particular e material, e que, partindo da solidariedade e das necessidades dos segmentos humanos marginalizados, traz consigo um potencial emancipatório no tocante a tais sujeitos.

Certamente, que o desafio está em transgredir o convencional e buscar valores emergentes (a nível do pensamento, da sensibilidade e da ação comportamental), provenientes das práticas sociais emancipatórias e das lutas reivindicatóirias por necessidades transformadas em direitos. No espaço aberto de interações renovadas e de exigências éticas, cuja realidade fragmentada e experimental é reinventada e rearticulada permanentemente, os movimentos sociais se legitimam para criar, produzir e definir princípios éticos de uma nova sociedade, pautados na emancipação, autonomia, solidariedade, justiça e dignidade de uma vida capaz da satisfação das necessidades fundamentais ${ }^{51}$.

\subsection{RACIONALIDADE COMO NECESSIDADE E EMANCIPAÇÃO}

Como último elemento, no âmbito da efetividade formal, Wolkmer propõe uma racionalidade emancipatória, sublinhando a importância de se descrever processos de conhecimento comprometidos com a emancipação e autonomia da 'essência humana ${ }^{52}$.

\footnotetext{
${ }^{49}$ Ibidem, p. 239.

${ }^{50}$ Ibidem, p. 240.

${ }^{51}$ Ibidem, p. 244.

${ }^{52}$ Constata que, se por um lado, o processo de racionalização moderna desencadeou grande
} 
Para tanto, o autor retoma alguns aspectos da discussão doutrinária que envolve a questão da racionalidade, passando da intepretação positiva de Max Weber, até chegar às interpertações negativas da tradição marxista, envolvendo Lukács, Adorno e Horkheimer, Marcuse e Habermas. Dentre esses autores, destaca-se a proposta de Habermas acerca da racionalidade comunicativa, o qual atesta que "a racionalidade moderna não está a serviço das relações de dominação e de interesses reprodutores da violência contra o 'mundo da vida', mas também espelha a superficialidade de valores e a desintegração atual da humanidade, mais do que nunca manipulada, constrangida e distorcida"53. Indo além da mera crítica à razão instrumental, Habermas propõe-se a solucionar as patologias sociais a partir de uma 'ação comunicativa', lastreada "no consenso não-coagido e na convicção recíproca", o que representa "o abandono da razão instrumental insuficiente por uma razão 'prático-discursiva', descentralizada, reconstruída e ampliada"54. Isso leva a uma alteração paradigmática, dado que a racionalidade não é mais faculdade abstrata do sujeito isolado, mas passa a ser implementada socialmente, a partir da interação entre os atores sociais. Wolkmer reconhece as contribuições dessa proposta ao transcender as formas particulares de racionalidade tecno-industrial, apesar de não a considerar imune à diversas críticas $^{55}$, demandando um ulterior desenvolvimento.

O que Wolkmer destaca é que as formulações teóricas que envolvem processos racionais devem partir das necessidades concretas e condições históricas geradas pelas práticas diárias, dado que "não nascem dos a prioris fundantes

desenvolvimento técnico, científico e material, gerou, também, a desintegração da condição humana, massificação, alienação e não foi capaz de evitar que o próprio progresso material afetasse a liberdade.

${ }^{53}$ Ibidem, p. 248.

${ }^{54}$ Ibidem, p. 250.

55 WOLKMER reconhece que há limites na implementação da teoria habermasiana nas sociedades periféricas, entre eles: a) a racionalidade comunicativa foi elaborada com base em sociedades capitalistas que alcançaram alto grau de riqueza e satisfação das necessidades; b) a ação e o entendimento comunicativo pressupõem sujeitos livres, conscientes, autônomos e iguais, o que não reflete a realidade desigual da América Latina; c) a dificuldade de se alcançar um consenso em espaços comunicativos periféricos, fragmentários e tensos, somado ao risco de um consenso forjado e manipulado por burocracias partidárias estatais ou pela indústria cultural de massas; d) requer uma comunidade de comunicação ideal, desprovida de mentira, coação ou irresponsabilidade, o que beira a utopia, com o risco de discursos emancipatórios artificiais; e) supervalorização da razão humana como agente de transformação e emancipação, minimizando os condicionamentos e irracionalismos inerentes às pessoas. Segundo WOLKMER (Ibidem, p. 252). 
universais, mas da contingência direta dos interesses e necessidades da pluralidade de ações humanas em permanente processo de interação e participação" ${ }^{\text {"56 }}$. Isso implica o abandono de qualquer racionalidade de ordem metafísica e tecnoformalista, para reconhecer que apenas a racionalidade que provém da vida concreta é que pode conduzir a uma razão emancipatória. Sua proposta vem, portanto, no sentido de "construir uma racionalidade como expressão de uma identidade cultural enquanto exigência e afirmação da liberdade, emancipação e autodeterminação",57.

Certamente, há que se pensar nas ferramentas para a implantação do pluralismo como paradigma de uma nova cultura político-jurídica, sendo que Wolkmer privilegia os mecanismos instrumentais capazes de romper com os obstáculos do velho paradigma e lançar as bases para "um novo homem, uma nova sociedade, um novo comportamento e um novo conhecimento". Nesse contexto, sublinha que a função maior para operacionalização desse projeto é dada por uma pedagogia libertadora "comprometida com o processo de desmistificação e conscientização (um novo 'desencanto do mundo'), apta a levar e a permitir, por meio da dinâmica interativa 'consciência, ação, relfexão-transformação', que as identidades individuais e coletivas assumam o papel de agentes históricos de juridicidade, fazendo e refazendo o mundo da vida, e ampliando os horizontes do poder societário"

\subsection{AINDA SOBRE A PROPOSTA PLURALISTA DE WOLKMER}

É sabido que o tema do pluralismo jurídico já foi alvo de muitos debates e estudos críticos, mas nem por isso parece menos atual, podendo ser compreendido de várias formas. Entende-se que, dentre as propostas existentes, as que melhor abordam a questão são aquelas que procuram valorizar a interação entre o plano da jurisdicidade emanada do Estado e o plano das práticas materiais emergentes do complexo tecido

\footnotetext{
${ }^{56}$ Ibidem, p. 252.

${ }^{57}$ Ibidem, p. 253.

${ }^{58}$ Ibidem, p. 253-254.
} 


\section{PLURALISMO JURÍDICO: UM NOVO PARADIGMA PARA SE PENSAR O FENÔMENO JURÍDICO}

das relações sociais. É nesse sentido que aparece a proposta de Antônio Carlos Wolkmer, como uma nova concepção de pluralismo jurídico apta a fundar um novo paradigma para o direito baseado em uma perspectiva democrática.

Uma proposta pluralista para o direito, quando comparada com os traços modernos ainda presentes no direito oficial, promove a ruptura e o questionamento acerca de dogmas, escolas e conceitos prontos que permeiam o cenário no qual o jurista contemporâneo atua. Wolkmer, a partir da constatação das insuficiências do paradigma moderno, procura apresentar as bases para a construção de uma nova racionalidade, fundada nas práticas sociais concretas e na emancipação e libertação das experiências plurais da sociedade ${ }^{59}$. Sua proposta vem articulada a partir de elementos de efetividade formal e material, direcionada à viabilização de um "Direito Comunitário", o qual, ao invés de subordinar-se à sistematização tecnoformal e aos procedimentos pré-estabelecidos, está sujeito à eficácia social.

Fica claro ao longo de sua obra que Wolkmer não propõe abolir o direito estatal até por considerar tal tarefa extremamente difícil no âmbito de uma tradição jurídica como a brasileira -, apesar de buscar uma ruptura com o paradigma vigente, sugerindo que o direito estatal passe a ser "controlado e tutelado pelos novos pólos normativos da vida cotidiana comunitária" ${ }^{\circ 0}$. Nessa linha, a relação entre direito positivo estatal e outras formas de expressão de juriscidade é modificada, pois o Estado passará a representar mais autenticamente a formalização das aspirações gerais emergentes da sociedade e se efetivará nesta, a partir das práticas sociais, com o que perde sentido - ou ganha um novo - a separação entre Estado e Sociedade ou mesmo entre Direito Público e Privado.

Wolkmer não deixa de enfrentar as dificuldades que surgiriam em caso de contradição entre Direito Comunitário e Direito Estatal, defendendo que, para além dos casos de complementação e interdependência entre ambos, a solução deve partir do critério do justo, tomando por parâmetro as aspirações legítimas e a satisfação das necessidades. Para que as condições para implementação de um direito justo sejam alcançadas, preocupa-

59 Representadas pelos movimentos sociais, chamados por WOLKMER de "novos movimentos sociais" porque pautados em uma racionalidade emancipadora.

${ }^{60}$ WOLKMER, op. cit., p. 315. 
se com a difusão de uma pedagogia emancipadora, tornando os sujeitos capazes de compreender que a fase atual é de transição paradigmática e que a proposta delineada não passa de um reconhecimento do que já existe informalmente na sociedade.

\section{CONSIDERAÇÕES FINAIS}

De fato, mister considerar que, na medida em que o modelo clássico - ainda vigente - de legalidade estatal apresenta-se insuficiente para solucionar satisfatoriamente os conflitos inerentes à realidade social, torna-se necessário o reconhecimento da possibilidade de que os novos atores sociais implementem instâncias de jurisdicidade extraestatal, descentralizadas. Tal proposta, marcada pelo surgimento de novos espaços de jurisdicidade paralelos ao Estado e estruturadas com base na efetividade social das medidas delineia o surgimento de um novo paradigma para o político e o jurídico.

O pluralismo jurídico, reconhecendo a existência de uma multiplicidade de formas de jurisdicidade heterogêneas que não se reduzem entre si, implica a aceitação de um Direito paralelo ao oficial, que surge das práticas comunitárias e que tem sua legitimidade assentada não no caráter estatal de sua fonte ou nos procedimentos formais préestabelecidos para sua validade, mas no reconhecimento e eficácia social que possui em uma comunidade.

$\mathrm{Na}$ realidade social brasileira - um país de dimensões continentais, marcado por profunda desigualdade social, falta de acesso aos serviços básicos e satisfação das necessidades essenciais a grande parte da população -, o modelo de racionalidade moderna, marcado pelo monismo na produção do Direito, tem sido insuficiente para atender às demandas da sociedade, em especial no que concerne às parcelas excluídas e marginalizadas. O Direito estatal, neste viés, mostra-se impotente por não conseguir atender às necessidades mais básicas da população e ausente porque divorciado das práticas sociais de expressiva parcela da população. Além disso, não parece mais viável 


\section{PLURALISMO JURÍDICO: UM NOVO PARADIGMA PARA SE PENSAR O FENÔMENO JURÍDICO}

a defesa de um formalismo exagerado e ultrapassado que reduz todas as fontes jurídicas à lei, sendo indispensável a constatação da pluralidade de fontes materiais do Direito.

Superando a identificação entre Direito e lei, passa-se a aceitar que aquele existe como forma de regulamentação social, ultrapassando os limites do aparato estatal para abranger "tudo aquilo que está intimamente ligado à pessoa e ao grupo social ao qual ela pertence" ${ }^{\text {61 }}$. Assim, a diversidade de formas de organização social faz surgir uma rede complexa de modos de regulação social, conduzindo a uma pluralidade de jurisdicidades. Isso não significa, porém, que não deva existir um centro unificador dessa diversidade, identificado na figura do Estado, pois, embora exista a possibilidade de ordens plurais e descentralizadas, parece impossível uma regulação global, que abranja todo um país, sem ser marcada por processos de abstração e generalização nos moldes da produção estatal.

É nesse contexto que parece interessante a proposta pluralista, no sentido de promover o reconhecimento das práticas e necessidades de segmentos sociais múltiplos e distintos que convivem em um mesmo espaço geopolítico, não parecendo mais factível a não-aceitação, por parte do Estado e seus instrumentos, da legitimidade das práticas sociais extraestatais surgidas, em grande parte, em função da inoperância do Estado e insuficiência do modelo paradigmático ainda em voga. Embora não elimine a possibilidade e a legitimidade de um Direito emandado do Estado, a constatação da diversidade social favorece a diversidade de consciências jurídicas e a emergência de fontes plurais do Direito, de modo que a não se reduzir o Direito ao Estado ou às concepções da classe politicamente dominante ${ }^{62}$.

É importante sublinhar, destarte, que, conforme adverte Maliska, a visão pluralista que parece ter mais consistência teórica e prática é aquela que "não apresenta uma visão de pluralismo que busca identificar toda e qualquer perspectiva de jurisdicidade emanada do Estado como burguesa, classista e comprometida com os

${ }^{61}$ MALISKA. Pluralismo ..., p. 112.

${ }^{62}$ Efetivamente, quando se fala em pluralismo jurídico não se quer referir ao pluralismo tradicional e conservador, que é elitista e inviabiliza a organização das massas, mascarando a verdadeira participação popular; defende-se um pluralismo progressista, que, na esteria da proposta de WOLKMER, "procura pomover e estimular a participação múltipla dos segmentos populares e dos novos sujeitos coletivos de base" (WOLKMER. Pluralismo jurídico: fundamentos ..., p. 321). 
interesses hegemônicos",63. Um pluralismo jurídico factível parece ser aquele que reconhece a legitimidade das conquistas já asseguradas no plano jurídico estatal e da contribuição que o operador jurídico atuante na estrutura jurisdicional existente pode oferecer com vistas à elaboração de um projeto social emancipatório.

Portanto, defende-se que o reconhecimento de fontes de jurisdicidade paralelas ao Estado caracterizadoras de um pluralismo jurídico não implica uma negação à ordem estatal; ao contrário, entende-se que há profunda interação entre ambas. Ao atuar no plano político, muitas vezes os movimentos sociais buscam uma aproximação com o Estado e a formalização de suas demandas, sem que com isso percam sua autonomia e independência. Mister reconhecer que, embora o monismo apresente limitações não mais compatíveis com o atual estágio de desenvolvimento e complexidade social, a formalização do Direito trouxe grandes conquistas, podendo-se citar, exmplificativamente, os princípios direcionados à defesa e promoção da dignidade da pessoa humana, entre outros consagrados nas modernas Constituições dos Estados, princípios estes que não pertencem a nenhuma classe social (e, portanto, não devem ser tomados como expressão exclusiva dos interesses burgueses). Da mesma forma, as instituições estatais - como as instâncias do Poder Judiciário, os representantes do povo que compõem as Casas do Poder Legislativo e os servidores do Poder Exevutivo - são indispensáveis para a implementação dos direitos humanos, satisfação das necessidades essenciais da população e proteção contra a violação dos princípios consagrados constitucionalmente, valendo destacar que, como indica MALISKA, o conservadorismo de algumas dessas instituições não parece ser motivo suficiente para inviabilizar as tentativas de democratizá-las e torná-las acessíveis aos cidadãos ${ }^{64}$.

Destarte, considera-se que o pluralismo jurídico aparece como um instrumento conducente à democratização e repolitização do Direito, parecendo equivocado, no entanto, tomá-lo como meio para negação do Estado ou das instituições já existentes. É justamente por aparecer nesse sentido que se destaca a importância e atualidade da proposta de Wolkmer, de um pluralismo jurídico comunitário democrático.

\footnotetext{
${ }^{63}$ MALISKA. Pluralismo ..., p. 109.

${ }^{64}$ Ibidem, p. 116-117.
} 
PLURALISMO JURÍDICO: UM NOVO PARADIGMA PARA SE PENSAR O FENÔMENO JURÍDICO

\section{REFERÊNCIAS}

CAPPELINI, Paolo. Il Códice eterno. La forma codici e suoi destinatari: morfolofie e matamorfosi di um paradigma della modernità. In: ; SORDI, Bernardo (a cura di). Codici: uma riflissione di fine millenio (atti dell'incontro di studio, Firenze, 26-28 ottobre 2000). Milano: Giuffrè, 2002.

EHRLICH, Eugen. Fundamentos da sociologia do direito. Trad. René Ernani Gertz. Rev. Vamireh Chacon. Brasília: UnB, 1986

GROSSI, Paolo. El ordem jurídico medieval. Trad. Francisco Tomas y Valente e Clara Álvares. Madrid: Marcial Pons, 1996.

. Mitologias jurídicas da modernidade. Trad. Arno Dal Ri Junior. Florianópolis: Boiteux, 2004.

MALISKA, Marcos Augusto. Pluralismo jurídico e direito moderno: notas para pensar a racionalidade jurídica na modernidade. Curitiba: Juruá, 2000.

. Introdução à sociologia do direito de Eugen Ehrlich. Curitiba: Juruá, 2001.

SANTOS, Boaventura de Souza. $O$ discurso e o poder: ensaio sobre a sociologia da retórica jurídica. Porto Alegre: Fabris, 1988.

WOLKMER, Antônio Carlos. Pluralismo jurídico: fundamentos de uma nova cultura do direito. 2. ed. São Paulo: Alfa-Omega, 1997.

PLURALISMO JURÍDICO. In: Dicionário de Filosofia do Direito. Vicente Barretto (org.). São Paulo: Unisinos; Rio de Janeiro: Renovar, 2006. 